\title{
Assessment of water logging and salinity problems in South Africa: an overview of Vaal harts irrigation scheme
}

\author{
O. I. Ojo ${ }^{1}$, G. M. Ochieng ${ }^{1}$ \& F. O. A. Otieno ${ }^{2}$ \\ ${ }^{1}$ Dept. of Civil Engineering, Tshwane University of Technology, \\ Pretoria, South Africa \\ ${ }^{2}$ Technology, Innovation and Partnerships Unit, \\ Durban University of Technology, South Africa
}

\begin{abstract}
Soil salinity and water logging are twin critical environmental problems in many countries around the world especially the arid and semi-arid countries like South Africa. These problems have a great impact on soil fertility which in turns has a great effect on soil productivity. Thus, this paper reviews water logging and salinity as irrigation problems in South Africa with emphasis on Vaal harts Irrigation scheme (VIS).

An estimated $0.62 \%$ of 776,131 ha of South Africa soils were discovered to be strongly saline according to literature. Also, an estimated $13-18 \%$ of the area under regular irrigation appears to be affected by water logging and salinization in VIS. It is situated between the Vaal and the Harts Rivers is approximately in the centre of the Republic of South Africa and also the largest irrigation scheme in the country with about 35,000 ha of land served as the case study for the assessment.

The most frequently used methods to assess, monitor and quantify water and salinity problems are by means of soil surveys, questionnaires and laboratory analyses. These traditional data collection methods are neither enough for the assessing these important environmental issues nor accurate for soil studies. The use of modern techniques such as aerial photography, GIS and remote sensing (RS) are on the increase. Remote sensing and satellite image data are used to overcome most of these limitations with a need to best find the calibration between the data and real field situations. Presently, research is in progress on the use of RS to investigate these problems in VIS. Land sat data and weather
\end{abstract}


data collected for the area from 1995 to 2009 have been analyzed with a view to recommend appropriate policy for further development in South Africa. Keywords: irrigation, salinity, water logging, Vaal harts, agriculture.

\section{Introduction}

Irrigated lands contribute significantly to the world agriculture output and food supply. Estimates in 1986 indicated that about half of the increase in agricultural production in the previous 35 years had come from irrigated land, about onethird of the world's crops were grown on the one-sixth of the cropped area which was irrigated, and the irrigated land was, on average, more than twice as productive as rain-fed land. Figures from 1996 estimated that developed countries, on average, irrigated $10 \%$ of their agricultural area, and countries in development $23 \%$, and combined they irrigated $18 \%$ of the total agricultural area [1].

Most of the soils with a high degree of irrigability occur in more arid regions. While about 1.4 million ha is irrigated at present, another 280000 ha of soil is suitable for irrigation but water availability dictate that only a further 178000 ha can be irrigated in future as estimated by Barnard et al. [2]. The commonly used methods of irrigation are flood irrigation $(28.5 \%$ of the total irrigated area), sprinkler on $53 \%$ and micro-irrigation on $18.5 \%$.

Barnard et al. [2] reported that irrigated agriculture is practiced by an estimated 40000 small-scale farmers, 15000 medium to large-scale farmers, 120000 permanent workers and variable numbers of seasonal workers and the dependants of all these. De Villiers et al. [3] also reported that medium and large-scale farmers irrigate approximately 1.2 million ha. Irrigation scheme-wise, this is represented by 450000 ha private schemes developed by land owners; 400000 ha irrigation board schemes; 350000 ha government schemes; 50000 ha distributed among 40000 small-scale farmers; and the balance of the area concerned is used by micro-scale schemes with garden and community plots.

\section{Irrigation problems}

Irrigated agriculture is a stabilizing factor in South Africa's food production scenario, responsible for $30 \%$ of total food production, irrigation-related salinisation results in a number of chemical-physical-biological problems jeopardizing sustainable irrigated agriculture. Water logging mostly associated with irrigation is an incessant countrywide problem while the salinisation of both soils and water is a threat to irrigated agriculture. Ahmad and Singh [4] reported that the problems of rising water table and salinization in the areas of canal irrigation projects have affected large irrigation countries such as India, Pakistan, Afghanistan, Egypt, Iran, Sudan, Syria and the USSR. India has lost several million hectares of land and about 15 million hectares of irrigated land are already suffering from salinization and water logging in Pakistan. They also stated that about half of the world's irrigated area has already been damaged to some degree by water logging and salinization and that much of the land 
expected to be irrigated in the future is highly vulnerable to similar damage, and at a global scale, at least 200000 to 300000 ha of irrigated land are lost every year due salinization and water logging.

De Villiers et al. [3] reported that irrigation schemes are beset with problems and that only $37 \%$ of the participants are commercially oriented. It is envisaged that soil degradation, and notably salinization and water logging could, in future, become a formidable problem jeopardizing the objectives concerning irrigated agriculture to create opportunities for smallholder and resource poor farmers by improving the efficiency and therefore the competitiveness of this sector. They also found in the Nkomazi irrigation scheme for small-scale farmers that water logging, salinity and sodicity had reduced agricultural productivity within one year of irrigation to such an extent that reclamation is inevitable.

\subsection{Salinization and water logging}

The salinization of soils results in a number of chemical, physical and biological problems. According to the South African database, an estimated 776131 ha of South African soils that is $0.62 \%$ are strongly saline while soils with weak profile development usually occurring on flood plains that can be saline, comprise 1447988 ha that is $0.62 \%$ [2]. They stated that salinity is most often associated with water logging and pollution caused by irrigation. Factors discovered to be involved in potential salination at irrigation schemes are soil suitability, poorly designed and operated irrigation systems, and water quantity and quality. According to a survey by the Department of Agriculture in 1990, out that 128000 ha of cultivated land 54000 ha is seriously alkaline and waterlogged and moderately affected. Bowonder et al. [5] stated that water logging and salinity are two major environmental problems that can arise in large irrigation projects.

\subsection{Soil pollution}

Soil pollution in South Africa is increasing as soil is the only medium to discharge of the ever increasing volume of solid waste products and effluent produced by the growing population, industrialization and urbanization. According to Barnard et al. [2], the biggest contributor to the solid waste stream is mining waste with $72 \%$, pulverized fuel ash with $6.7 \%$, urban waste with $4.5 \%$ and sewage sludge with $3.6 \%$. The contribution of agriculture to the solid waste stream is an estimated $0.002 \%$. Water quality is in jeopardy as a result of pollution, as water is a limited and strategic resource. Urbanization, industrialization, irrigation, inorganic fertilizers, weedicides and pesticides used by agriculture, polluted return flows and the recycling of water, largely contribute to water quality deterioration. Van der Merwe [6] also noted the particular importance of an increasingly heavy mineral salt load as salinity as it renders water less suitable for urban and industrial use while it has a devastating effect on food crops. 


\section{Study area: Vaal harts irrigation scheme}

The Vaal harts Irrigation Scheme (VIS) covers about 36950 ha and is one of the largest areas in the world. Water is provided to some 680 farmers [7]. The scheme is supplied with water abstracted from Vaal River at the Vaal harts weir about $8 \mathrm{~km}$ upstream of Warrenton.

VIS is located in a summer rainfall area. This area battles with low, seasonal and irregular rainfall. The average rainfall is $442 \mathrm{~mm} /$ year [8]. The average precipitation in summer months, October to February differs between 9.1 and $9.6 \mathrm{~mm} /$ day while in July precipitation is only $3.6 \mathrm{~mm} /$ day. The water quota for

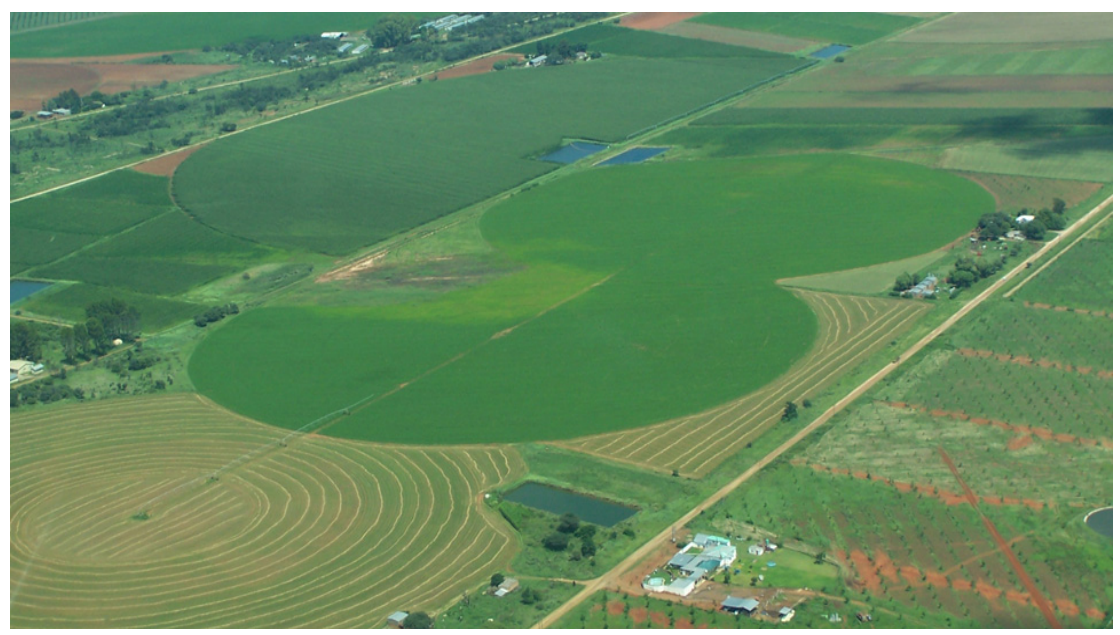

Figure 1: $\quad$ Aerial overview of VIS [9].

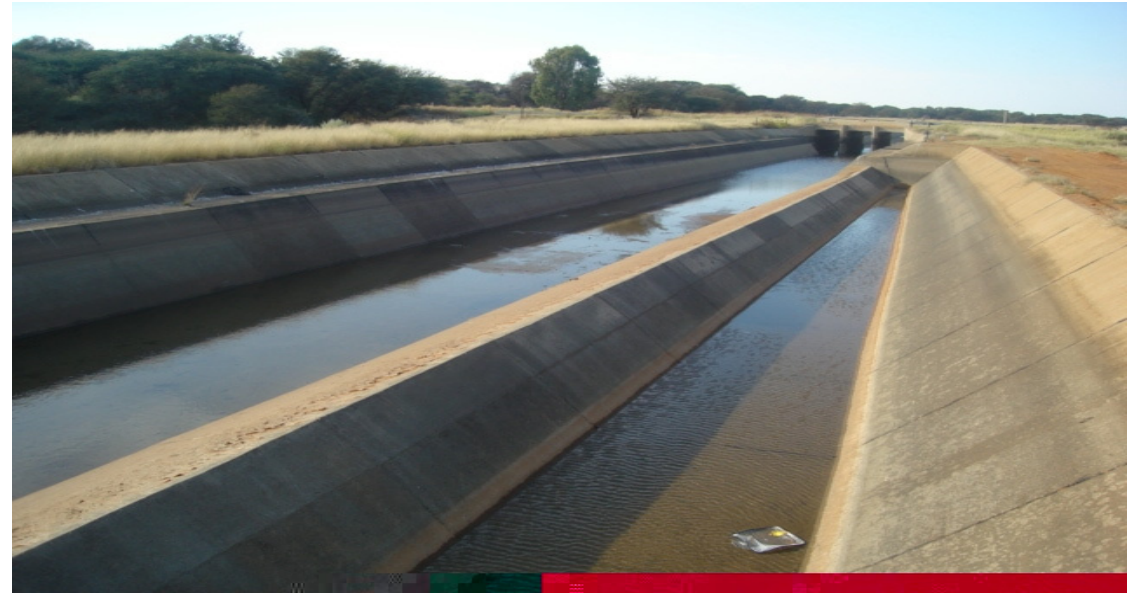

Figure 2a: VIS main canal with low level of water. 


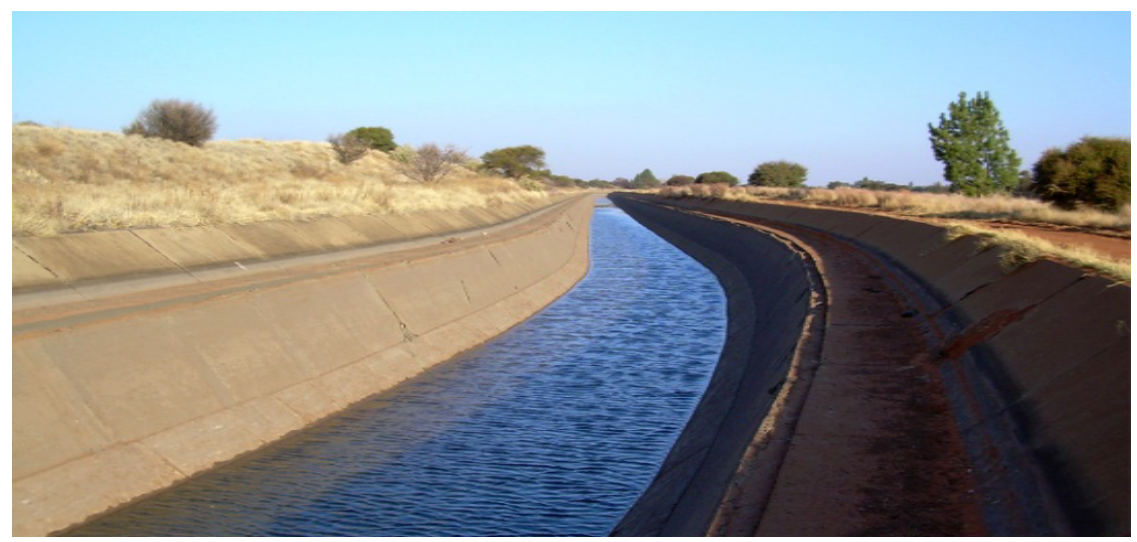

Figure 2b: VIS main canal [9].

the North and West canal is $9140 \mathrm{~m}^{3} / \mathrm{ha} /$ annum. The total water use charge is 8.77 cents per cubic meter of water which consists of a charge of 8.24 cents for irrigation water use, a catchment management charge of 0.5 cents per cubic meter and a water research charge of 0.03 cents per cubic meter of water [7]. VIS is relatively flat, although its slope gently towards the Harts River, leaving the area as a basin. It lies within a valley with maximum and minimum altitudes of 1150 masi and 1050 masi respectively. The climate in the region is semi-arid to arid, with rainfall ranging from $500 \mathrm{~mm}$ to less than $200 \mathrm{~mm}$ per annual and evaporation reaching $2800 \mathrm{~mm}$ per annual towards the west. The common crops grown in the area are wheat/barley, maize, groundnuts, cotton and other permanent crops like Lucerne, Pecan nuts, grapes, olives and some other fruits.

\subsection{Irrigation problems in VIS}

According to Streutker et al. [10] flood irrigation commenced at the Vaal harts Irrigation Scheme of 30000 ha established in 1940 and soon after, the groundwater table rose to between 0.9 and $1.5 \mathrm{~m}$ over the whole area. In 1956 several salinisation cases were reported and in the 1960s, a number of soil profiles from all over the Scheme, contained more salts in the subsurface than measured during the initial soil survey, indicating a disturbing tendency, although not alarming at that stage. Within 35 years the fine, sandy soils of this scheme were severely salinised. They reported on the reclamation of some 30000 ha saline or saline-sodic soils (depth $0.3 \mathrm{~m}$ ) at the VIS. Salt-affected soils resulted in a South African Rand R1.4-R2.1 loss in gross income for the irrigation scheme farmers. The installation of 218 drainage systems totaling 500 $\mathrm{km}$ of subsurface lateral drains at a cost of R2 million were undertaken between 1975 and 1977. Although the subsurface drains were successful in keeping the groundwater table below $0.7 \mathrm{~m}$ and leaching salts from recently salinised patches, there were still some 1500 ha of saline soils by the end of 1977 and 1000 ha in 1980. Bearing in mind that an estimated 100000 ha of the 885000 ha of the land of State Irrigation Schemes were salt-affected by 1976, the cost of 
reclamation is justified only if maintenance of the water table does not require a considerable amount of over-irrigation and does not cause pollution down-stream which requires a high level of irrigation and drainage management. In the period 1974-1976, the semi-arid Vaal harts area (218 farms) received above average rainfall resulting in a critical level of soil salinisation. Surface storm water did not drain fast enough and the water table quite often rose to $0.3-0.6 \mathrm{~m}$ from the soil surface. Farmers started depending on the high water table and ignored leakage as well as drainage planning and continued over-irrigation with devastating effects. A further R2 million then had to be invested to install subsurface drains on farms and to link these drains to the partially developed system of open storm water drains, in an attempt to lower the water table and to leach salts $[10,11]$.

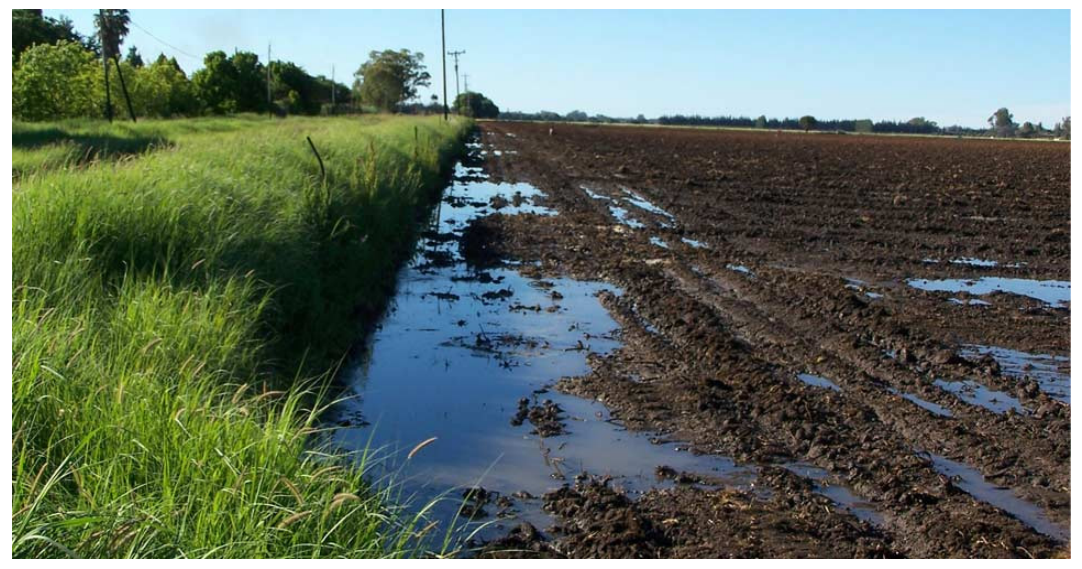

Figure 3: Waterlogged irrigation field in VIS [9].

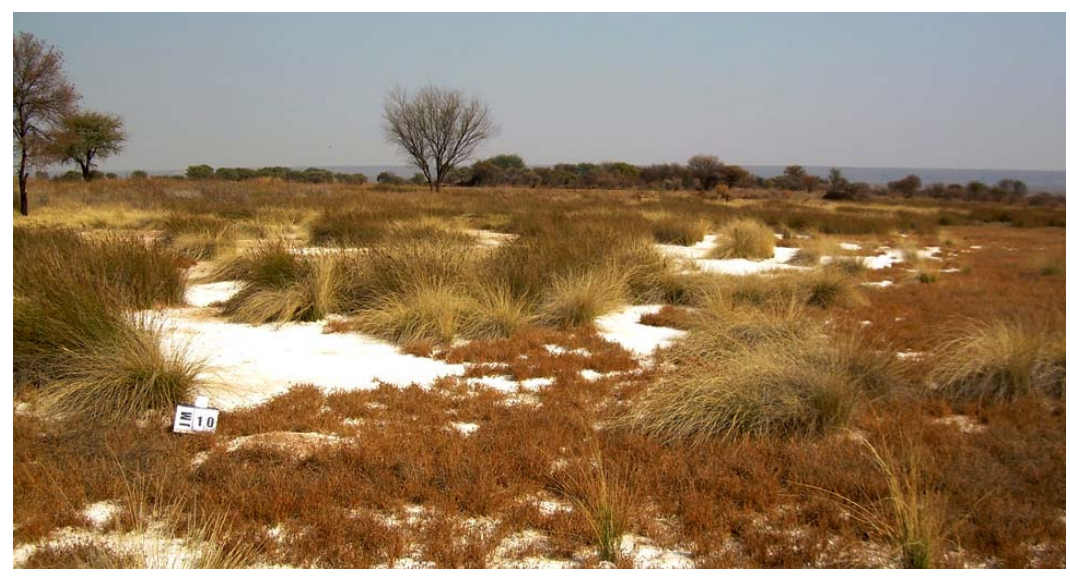

Figure 4: $\quad$ Salined area in VIS [9]. 


\section{Modern assessment tool: satellite remote sensing, GIS and wireless sensor}

Remote sensing is increasingly becoming useful for more applications in mapping, because the new generation of satellites now being launched carries instruments with much greater spatial resolution (as high as $0.6 \mathrm{~m}$ to $1 \mathrm{~m}$ ); sufficient to see many more features of interest in mapping than it was before now [12]. The same class of objects radiates electromagnetic energy of different wave lengths depending on its other features. Thus, soil as a class may comprise different types of particles, may be dry or wet, and may have different chemical properties and so on.

A GIS is commonly defined as a computer system for the input, editing, storage, maintenance, management, retrieval, analysis, synthesis and output of geographically referenced or spatial information [13]. GIS is a tool to analyze and interpret the remotely sensed data. It can also be used for the analysis and interpretation of physically collected data as well. In the developed countries like UK, US, Australia and the developing countries like India and Egypt, the use of remote satellite sensing (SRS), geographical information system (GIS), global positional system (GPS) and models have been integrated to better assess, monitor and quantify irrigation problems and thereby get irrigated farmers equipped for the day to day running of the scheme because the cost of collecting data using the current methods is labour intensive and expensive. The wireless sensor networks are a new technology for collecting data about natural or built environment. They consist of low cost embedded sensory and computational devices (audio and video which detect bio-chemicals in novel ways) with wireless capability forming ad hoc networks that provide information on an unprecedented temporal and spatial scale with the aim to reduce the cost of data capture by a factor of 1000 and increase the spatial and temporal resolution by a factor of 1000 within ten years. The sensor will allow greater understanding accurate monitoring and modeling, better prediction, planning and control sustainable management [14].

South Africa is making a progress in its systematic national system to monitor the impact of irrigated agriculture and the pace of salinization and water logging with the recent establishment of the SANSA: a national monitoring system developed and implemented for South Africa to modernize these techniques and make the data more available and accessible to end users. At Tshwane University of Technology, South Africa presently, remote sensed data are being collected using Landsat 7 ETM+ to assess, analysis and model environmental impacts of Vaalharts irrigation scheme in South Africa so as to help policies makers and planners on irrigation schemes within the context of environmental sustainability.

\section{References}

[1] Scotney, D.M. \& Dijkhuis, F.J., 1990. Changes in the fertility status of South African soils. S. Afr. J. Science 86, 395-402. 
[2] Barnard, R.O., Van der Merwe, A.J., Nell, J.P., De Villiers, M.C., Van der Merwe, G.M.E. \& Mulibana, N.E., 2002. Technical country report/in-depth study on problem soils including degraded soils in South Africa: Extent, present use, management and rehabilitation (with emphasis on salt-affected soils). $4^{\text {th }}$ Meeting of FAO Global Network Integrated Soil Management for Sustainable Use of Salt-Affected Soils. Valencia, Spain. May 2001.

[3] M.C. De Villiers, D.J. Pretorius, R.O. Barnard, A.J. Van Zyl, and C.F Le Clus, 2002. Land degradation assessment in dry land areas: South Africa. FAO Land Degradation Assessment in Dry land Project. Rome, Italy.

[4] Ahmad A. and P.P. Singh (1991). Environmental Impact Assessment for sustainable development: Chittaurgarh Irrigation Project in Outer Himalayas. JSTOR: Ambio, Vol. 20, No. 7 pp. 298-302.

[5] Bowonder B, K V Ramana and R Rajagopal (1986): Waterlogging in irrigation projects. Sadhana Volume 9, Number 3, 177-190, DOI: 10.1007/BF02811964. India

[6] Van der Merwe, A.J., 1995. Wise land use: The basis for sustainable growth and development in South Africa. Proc. ARC-ISCW Wise Land Use Symp. 2-8. Pretoria, South Africa.

[7] Grove, B., 2006. Generalised whole-farm stochastic dynamic programming model to optimise agricultural water use. Report to the Water Research Commission. Pretoria, Water Research Commission.

[8] Jager, J.M., 1994. Accuracy of vegetation evaporation formulae for estimating final wheat yield. Water SA, 20:307-314.

[9] Aurecon 2011. Vaal harts Irrigation scheme study. http://www.aurecongroup.com/en/Projects/Water/Vaalharts-Irrigation-

Scheme-Study.aspx Assessed on:25 march, 2011

[10] Streutker A., H.W. Molenaar, H. Hamman, C.C Nel, and J.H. Mulder. Besproeiing, gewasopbrengs en dreinering op die Vaalhartsbesproeiingskema: 2. Die voorkoms van verbrakte grond en die invloed van dreinering daarop. Water S.A. 7(3), 175-184. 1981.

[11] Du Plessis, H.M., 1991. Researching and applying methods to conserve natural irrigation resources. Proc. Sth. Afr. Irrig. Symp. 61-69. June 1991. Durban, South Africa.

[12] Akinyede, J.O. and Boroffice, R.A. (2004). Geoinformation, space application and sustainable national development. Nigerian journal of surveying and Geoinformatics Vol. 1 No.1 pp17-40.

[13] ESRI (1998). Introduction to ARCView GIS. Environmental system research institute. Inc. USA.

[14] CSIRO (2009). Wireless sensor networks: a new instrument for observing our world. www.csiro.au/science/Sensors-and-network-technologies.html. Accessed on 26th May, 2009. 